03

\title{
Исследование динамических процессов, реализующихся при генерации плазмоидных образований в сверхзвуковом потоке
}

\author{
() И.А. Знаменская, Д.С. Наумов, Н.Н. Сысоев, В.А. Черников \\ Московский государственный университет им. М.В. Ломоносова, фризический фракультет, \\ 119234 Москва, Россия \\ e-mail: znamen@phys.msu.ru
}

Поступило в Редакцию 29 сентября 2018 г.

В окончательной редакции 29 сентября 2018 г.

Принято к публикации 23 октября 2018г.

На основе высокоскоростной цифровой регистрации изображений проведен анализ плазмодинамических процессов и быстропротекающих ударно-волновых процессов, сопровождающих генерацию плазменного образования в сверхзвуковом струйном течении. Исследована с высоким временным разрешением динамика шарового плазмоидного образования, генерируемых им разрывов и их воздействие на головную ударную волну перед моделью. Показано, что на время существования плазмоида (около 100-120 $\mu$ s) меняется режим сверхзвукового обтекания модели - перестраивается ударный слой, значение отхода головной волны на оси симметрии существенно увеличивается за счет изменения структуры и параметров набегающего потока.

DOI: 10.21883/JTF.2019.06.47631.349-18

\section{Введение}

Цель настоящей работы - исследование возможности использования плазмоидных образований для изменения сверхзвукового течения около модели. Данной проблеме посвящено достаточно много работ [1-9]. Возможность управления обтеканием тел с помощью локализованного подвода энергии в сверхзвуковой поток рассматривалась численно в работах [1,2]. В [3] рассмотрена задача изменения параметров сверхзвукового обтекания полуцилиндрического тела экспериментально и численно на основе увеличения степени неравновесности набегающего потока. Сравнение полученных экспериментальных и расчетных данных позволило сделать вывод о возможном новом механизме управления сверхзвуковым потоком, связанном с повышением степени неравновесности газа в источнике энергии. В работе [4] изучено влияние тепловых пятен, созданных микроволновым и лазерным излучениями, на сверхзвуковое обтекание затупленных тел при числах Маха до 3.45, предложены подходы к уменьшению силы лобового сопротивления. Экспериментальные данные по структуре потока, возникающего при взаимодействии головной ударной волны с областью нагрева дуговым разрядом, приведены в работе [5]. Проанализированы оптимальные параметры энергоподвода, позволяющие существенно снизить лобовое сопротивление. Экспериментальному и численному исследованиям воздействия импульсного энергоподвода на высокоскоростные течения на основе наносекундных разрядов посвящены работы [6-8], частотный режим анализируется в работах $[8,9]$.

\section{Экспериментальная установка и условия проведения экспериментов}

В настоящей работе проведены экспериментальные исследования плазмодинамических процессов и быст- ропротекающих ударно-волновых процессов, сопровождающих генерацию плазменного образования в сверхзвуковом струйном течении. Исследования проводились на основе высокоскоростной цифровой оптической регистрации: 1 - свечения плазменного образования; 2 - теневой скоростной видеосъемки поля течения с разрывами. Блок-схема экспериментальной установки, предназначенной для исследования процесса взаимодействия плазмы, созданной импульсным генератором, со сверхзвуковым потоком воздуха приведена на рис. 1 .

Сверхзвуковое сопло Лаваля (рассчитанное для числа Maха $\mathrm{M=2)}$ и генератор плазмы, работающий по принципу магнитоплазменного компрессора (МПК) размещались внутри камеры низкого давления 1. Высокое давление на входе сопла создавалось при помощи компрессора и могло изменяться от 0.2 до $0.5 \mathrm{MPa}$. Давление на вход сопла подавалось при помощи управляемого

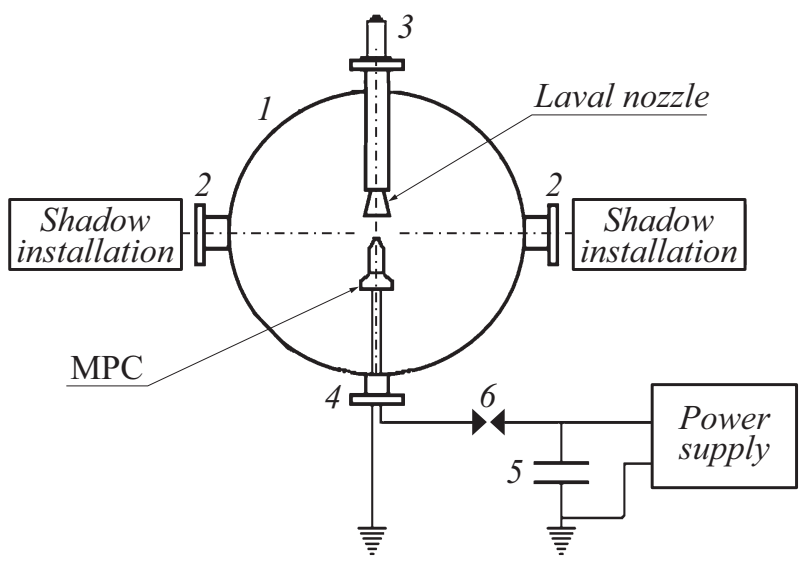

Рис. 1. Схема экспериментальной установки: 1 - камера низкого давления, 2 - иллюминаторы, 3 - штуцер высокого давления, 4 - герморазъем питания МПК, 5 - накопительный конденсатор, 6 - разрядник. 
клапана через штуцер 3. Питание к магнитоплазменному компрессору подавалось через герморазъем 4. Накопительный конденсатор МПК 5 заряжался от источника питания с максимальным напряжением $5 \mathrm{kV}$. При подаче высоковольтного импульса на разрядник 6 , напряжение питания подавалось на МПК, и происходил его разряд с генерацией плазменной струи.

Основные параметры разряда: длительность первого квазипериода тока $\sim 70 \mu \mathrm{s}$, максимальный ток $\sim 12 \mathrm{kA}$, падение напряжения на разряде $\sim 700 \mathrm{~V}$. Характерные параметры плазменного образования [10]: интегральная по времени температура плазмы $\sim 1.2 \mathrm{eV}$, средняя плотность электронов $\left(10^{15}-10^{16}\right) \mathrm{cm}^{-3}$, начальная скорость распространения плазмы вдоль оси разряда в неподвижном воздухе - около $1.5 \mathrm{~km} / \mathrm{s}$.

В описываемых экспериментах использовалась конструкция коаксиального МПК, при которой часть МПК, направленная навстречу потоку, была выполнена в виде усеченного конуса. Это позволило более четко фиксировать головную ударную волну на передней кромке МПК в набегающем из сопла сверхзвуковом потоке.

Для регистрации процесса взаимодействия плазмы, созданной магнитоплазменным компрессором (МПК) со сверхзвуковым потоком, использовалась теневая установка, собранная по классической схеме Теплера [11]. Теневая установка состояла из двух независимых частей: осветительной, которая создает параллельный световой пучок, и регистрирующей, в которой собственно и фиксируются пространственные и временные изменения показателя преломления среды в области между объективами. Теневая установка размещалась по обе стороны камеры низкого давления 1 напротив оптических иллюминаторов 2 таким образом, что осветительная часть установки находилась по одну строну камеры, а приемная - по другую. Сверхзвуковое сопло Лаваля и генератор плазмы (МПК) размещались внутри камеры низкого давления на одной оси, проходящей как по центру сопла, так и по центру генератора, при этом общая ось системы сопло-генератор находилась по центру светового поля теневой установки и была перпендикулярна направлению световых лучей.

Для синхронизации работы всех используемых элементов использовалась система, которая вырабатывала, прежде всего, импульс на открытие клапана высокого давления. Затем с задержкой около $200 \mathrm{~ms}$ подавался импульс на высокоскоростную камеру для запуска съемки, и с задержкой $\sim 100 \mu$ s относительно этого импульса подавался импульс на запуск разрядника МПК.

Для съемки процесса развития плазменного образования и его взаимодействия со сверхзвуковым потоком использовалась система цифровой регистрации с высоким временным и пространственным разрешением поля течения. Использовалась высокоскоростная цифровая камера FASTCAM SA5. Камера обеспечивает скорость съемки $7500 \mathrm{frame} / \mathrm{s}$ при разрешении $1024 \times 1000$, и максимальную скорость съемки $775000 \mathrm{frame} / \mathrm{s}$ при уменьшенном разрешении. Время экспозиции одного кадра около $1 \mu \mathrm{s}$. Объем памяти для записи информации до $64 \mathrm{~Gb}$; это позволяло снимать фильм длительностью до $3 \mathrm{~s}$, включая все стадии газодинамического процесса.

\section{Экспериментальные характеристики тока разряда}

Измеренное по осциллограммам время нарастания тока разряда плазмоидного образования - около $5 \mu \mathrm{s}$ (рис. 2). Такой быстрый ввод электрической энергии в газ, реализуемый в плазмоиде, приводит к образованию ударных (взрывных) волн, движущихся из зоны инициирования разряда со сверхзвуковыми скоростями и существенно влияющими на поток.

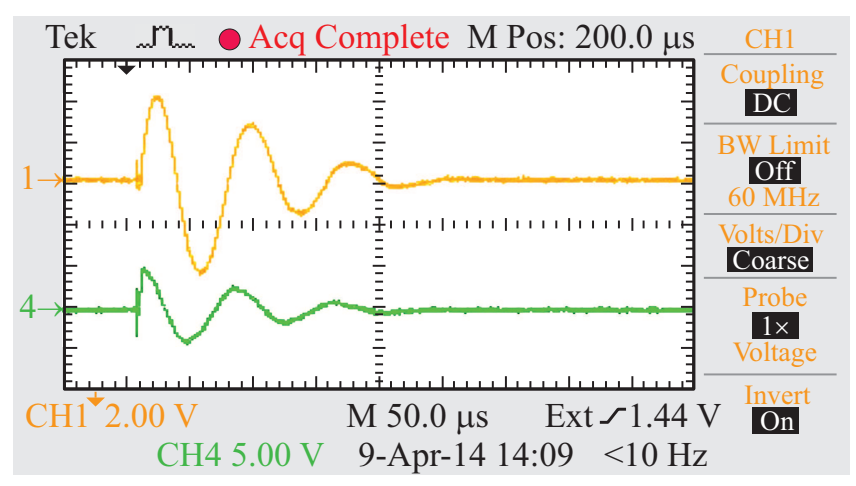

Рис. 2. Осциллограмма тока.
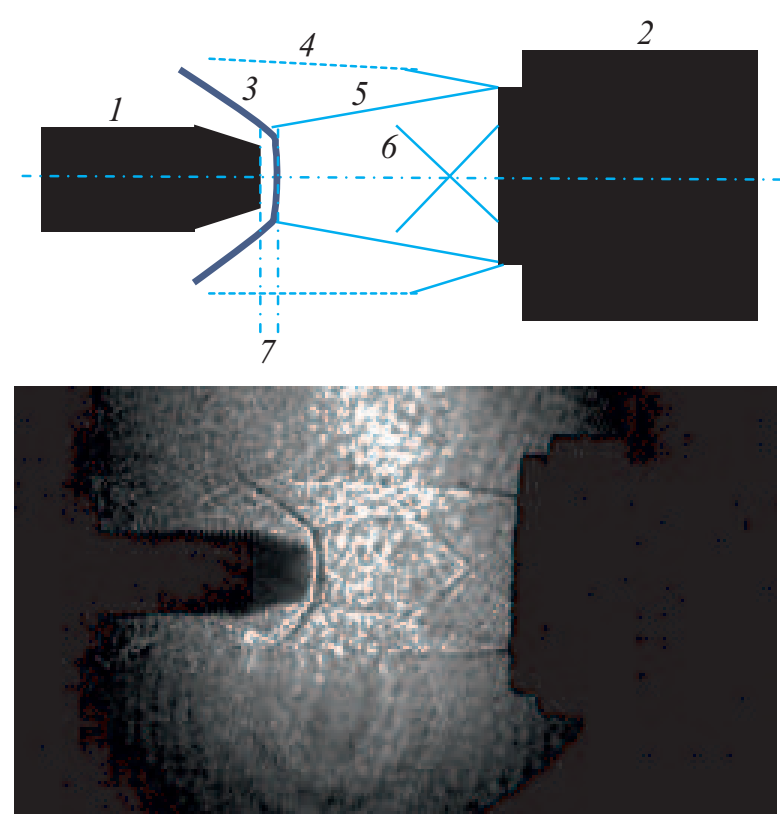

Рис. 3. Схема сверхзвукового течения (до инициирования плазменного образования): 1 - обтекаемый генератор плазменного образования, 2 - сверхзвуковое сопло, 3 - головная ударная волна, 4 - внешняя граница слоя смешения, 5 внутренняя граница слоя смешения, $6-$ висячие скачки уплотнения, 7 - величина отхода головной ударной волны. 

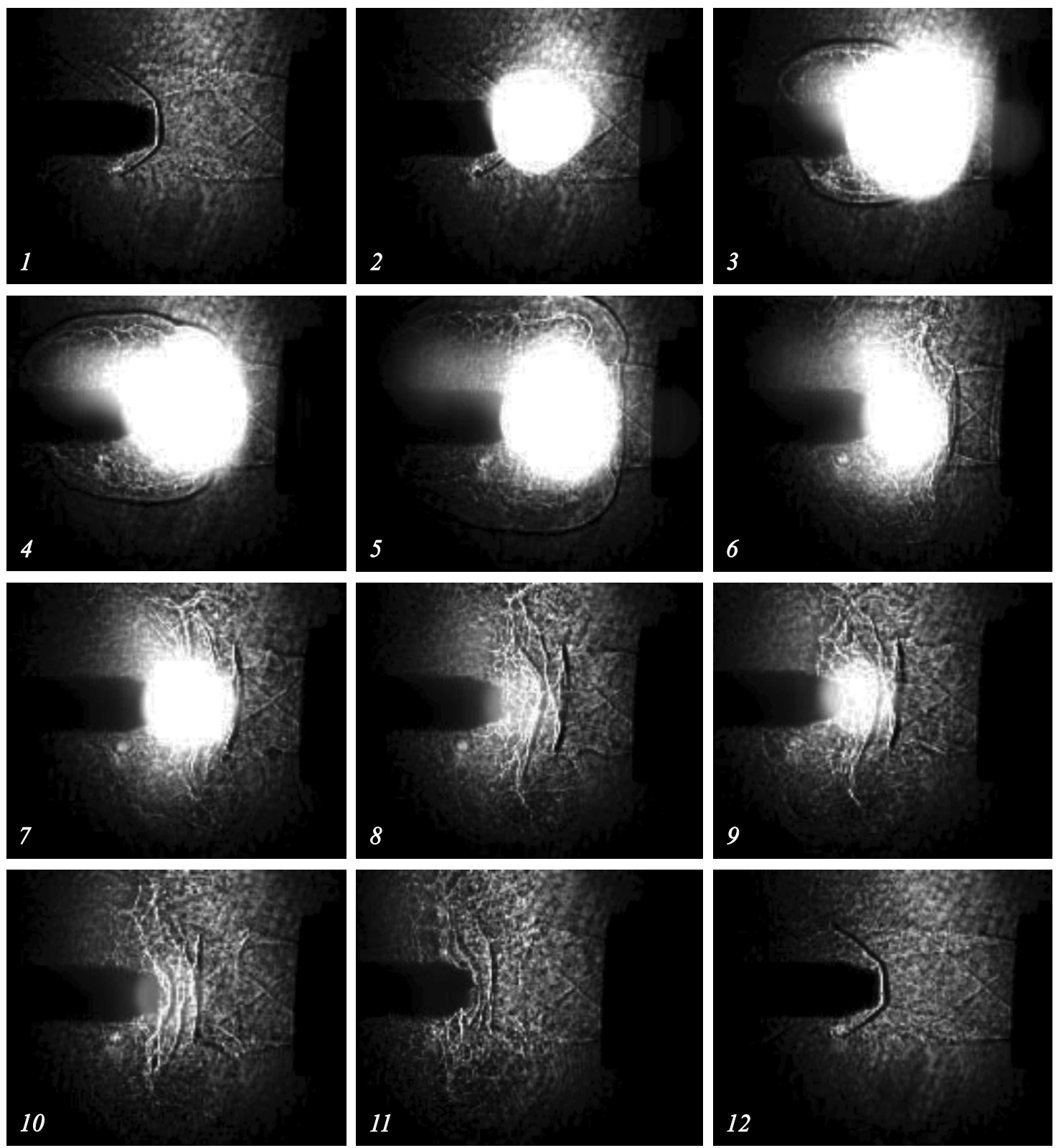

Рис. 4. Теневые изображения процесса.

\section{Регистрация ударно-волновых структур, генерируемых плазмойдным образованием}

Была проведена покадровая съемка процесса взаимодействия плазмоидных образований и возникающего при их генерации течения с областью сверхзвукового потока с головной ударной волной перед моделью в течение промежутков времени 150-200 $\mu$ s после инициирования плазмоида для различных значений скорости потока, истекающего из сопла; напряжения и тока. Использовались режимы съемки 150000 к/s и $325000 \mathrm{frame} / \mathrm{s}$, интервал между кадрами составлял соответственно около 7 и около $4 \mu \mathrm{s}$. Получены видеофильмы нестационарного процесса, включающие установление обтекания с голов- ной ударной волной перед генератором, возникновение и эволюцию плазменного образования, генерацию взрывных волн и их взаимодействие с потоком, восстановление исходной газодинамической конфигурации.

Через некоторое время после начала истечения сверхзвукового потока из сопла и его взаимодействия с препятствием (корпусом плазмотрона) устанавливается стабильное сверхзвуковое обтекание препятствия с отошедшей головной ударной волной. На рис. 3, $a$ приведена схема течения и обозначены основные структурные элементы. Течение имеет ось симметрии. На рис. $3, b$ представлен теневой кадр стадии стационарного обтекания плазмотрона (до инициирования тока разряда) с головной ударной волной, образовавшейся в результате обтекания генератора сверхзвуковой струей 
из сопла. Число Маха потока при набегании на тело $\mathrm{M}=3 \pm 0.1$. Измеренная по теневым снимкам величина отхода головной ударной волны от тела при этом составляет около $2 \mathrm{~mm}$.

На рис. 4 (1-12) приведены кадры процесса, полученные в одном из экспериментов. За момент времени $t=0$ взято время инициирования тока разряда. После инициирования разряда (рис. 4,$2 ; t=6.5 \mu \mathrm{s}$ ) на изображениях видно растущее в течение времени до $10 \mu$ s плазменное образование; возникает засветка излучением плазмы области головной ударной волны и носовой части плазмотрона Форма плазмоидного образования близка к сферической. Через некоторое время после инициирования тока разряда $(20-25 \mu \mathrm{s})$ становятся различимы боковые участки взрывной (ударной) волны, образованной импульсным энерговкладом в области плазменного образования, движущиеся от зоны плазмы (рис. 4,$3 ; t=26.5 \mu \mathrm{s}$ ). Взрывная волна имеет несферическую форму, так как ее часть вблизи оси симметрии течения взаимодействует со сверхзвуковым течением из сопла (рис. 4,$5 ; t=66 \mu \mathrm{s}$ ). По бокам идет взаимодействие $\mathrm{c}$ цилиндрической ударной волной ограничивающей струю из сопла (бочкой Маха). В результате догонного взаимодействия взрывной волны от плазмоида и головной ударной волны образуются новые разрывы вблизи оси симметрии течения: две ударные волны и контактная поверхность, разделяющая область газа и плазмы. Прошедшая ударная волна движется вверх по потоку к соплу, отражается от него, отраженная ударная волна движется назад к плазмотрону. На рис. $4,7(t=73 \mu \mathrm{s})$ видна отраженная от сопла, движущаяся справа налево ударная волна. Одновременно справа от плазмоида становится видна новая головная ударная волна, сформировавшаяся перед квазистационарным плазменным образованием. Ее кривизна значительно меньше, чем кривизна головной ударной волны в начальный момент времени. Видимая величина отхода головной ударной волны от тела при этом увеличилась примерно на размер плазменного образования. Это означает существенное снижение числа Маха обтекания (преимущественно за счет увеличения скорости звука в области плазмы).

Виден цуг ударных волн и возмущений малой кривизны, которые, сносимые потоком, приближаются к телу, взаимодействуют и формируют головную ударную волну перед телом (аналогичную исходной волне при $t<0)$. Через $t=170-200 \mu$ s окончательно устанавливается квазистационарное обтекание модели с головной ударной волной перед плазменным генератором. Величина ударного слоя при этом возвращается к исходному размеру в $2 \mathrm{~mm}$ в соответствии с числом Маха струи сопла в начальной конфигурации.

На рис. 5 приведена экспериментально полученная зависимость усредненного диаметра регистрируемой камерой светящейся области плазменного образования от времени. Размер области около $4 \mathrm{~cm}$ сохраняется в течение примерно $70 \mu \mathrm{s}$, при этом внутри образования неравновесная плазма очевидно неоднородна и

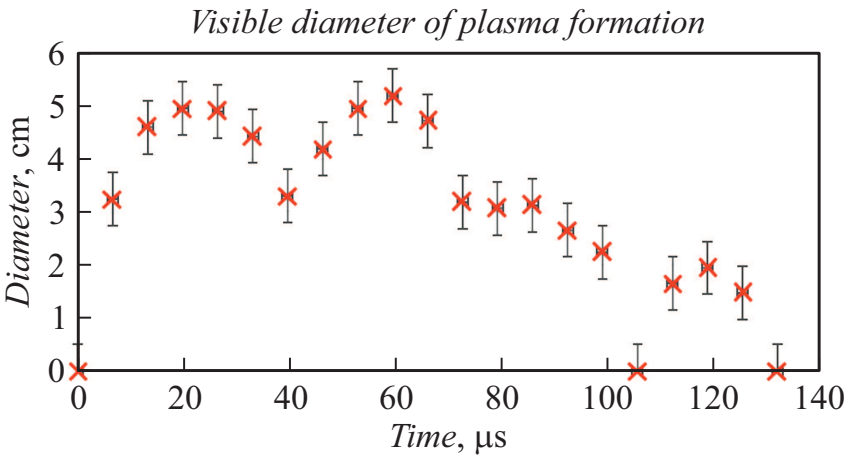

Рис. 5. Динамика размера плазменного образования.
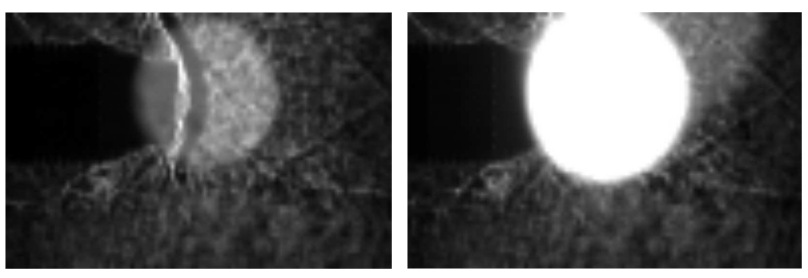

Рис. 6. Теневые изображения при скорости съемки 325000 frame/s.

нестабильна, постоянно генерирует звуковые возмущения (рис. $4,3,4,4)$. Анализ осциллограмм показывает, что после $100 \mu \mathrm{s}$ ток разряда затухает. На теневых кадрах процесса зарегистрировано начало ослабления интенсивности свечения плазмы после $100 \mu \mathrm{s}$ (рис. 4,8 ; $t=101 \mu \mathrm{s}$, рис. $4,7-132 \mu \mathrm{s})$. При этом интенсивность свечения плазмоида пульсирует во времени, коррелируя, как и размер плазменного образования, со значением тока разряда. Послесвечение плазмы после окончания протекания тока разряда продолжает регистрироваться камерой вплоть до $120-160 \mu \mathrm{s}$.

Визуализация процесса, проведенная с большей частотой теневой съемки, позволила уточнить временные характеристики быстропротекающего процесса, в основном связанного с динамикой плазменного образования. При этом за счет одновременного снижения пространственного разрешения изображения разрывов при визуализации газодинамического потока получены с меньшей четкостью.

На рис. 6 представлены 2 снимка свечения шарового плазмоида на начальной стадии его генерации. Интервал между 2 кадрами $4 \mu \mathrm{s}$. На первом кадре в отсутствии пересветки хорошо видна область локализации шарообразного плазменного образования.

\section{Заключение}

Таким образом, анализ результатов при высокой повторяемости полученных данных эксперимента в исследованном диапазоне параметров тока, напряжения, давления, скорости набегающего потока позволяет сделать 
следующие выводы. После генерации квазистационарного шаровидного плазменного образования на оси симметрии сверхзвукового струйного течения с головной ударной волной перед затупленным конусом (генератором плазмоида) на время протекания тока разряда (около 100-120 $\mu \mathrm{s}$ ) меняется режим и конфигурация сверхзвукового обтекания модели. За счет малого времени выделения энергии в области инициирования разряда возникают взрывные волны, их динамика определяет нестационарную стадию процесса. Перед обтекаемым телом перестраивается ударный слой, значение отхода головной волны на оси симметрии увеличивается в несколько раз - на величину диаметра плазмоида. Пульсации размеров и интенсивности свечения плазменного образования, а также слабые возмущения, генерируемые из зоны плазмоида, коррелируют с пульсациями тока разряда. Через $150-170 \mu \mathrm{s}$ (после окончания тока разряда) восстанавливается исходный режим сверхзвукового обтекания.

\section{Финансирование работы}

Работа выполнена при частичной поддержке гранта РНФ 18-19-00672.

\section{Список литературы}

[1] Георгиевский П.Ю., Левин В.А. // Известия РАН. Механика жидкости и газа. 2003. № 5. С. 154-167.

[2] Гувернюк С.В. // Письма в ЖТФ. 1997. Т. 23. Вып. 9. C. 1-8.

[3] Azarova O.A., Knight D.D. // Aerospace Sci. Technol. 2017. Vol. 64. N 1. P. 154-160.

[4] Азарова О.А., Ерофеев А.В., Лапушкина Т.А. // Письма в ЖТФ. 2017. Т. 43. Вып. 8. С. 93-101.

[5] Schülein E., Zheltovodov A. // Shock Waves. 2011. Vol. 21. N 4. P. 383-396.

[6] Mursenkova I.V., Znamenskaya I.A., Lutsky A.E. // J. Phys. D - Appl. Phys. 2018. Vol. 51. N 10. P. 105201(1)-105201(11).

[7] Znamenskaya I.A., Koroteev D.A., Lutsky A.E. // Phys. Fluid. 2008. Vol. 20. P. 056101-1-056101-6.

[8] Аульченко С.М., Замураев В.П., Знаменская И.А., Калинина А.П., Орлов Д.М., Сысоев Н.Н. // ЖТФ. 2009. Т. 79. Вып. 3. С. 17-27.

[9] Аульченко С.М., Замураев В.П., Калинина А.П. // ЖТФ. 2013. Т. 83. Вып. 4. С. 24-28.

[10] Ершов А.П., Колесников Е.Б., Тимофеев И.Б., Черников В.А., Чувашев С.Н., Шибков В.М. // ТВТ. 2006. Т. 44. № 4. C. 485-493.

[11] Васильев Л.А. Теневые методы. М.: Наука, 1967. 408 с. 